\title{
Suspension for Spray Dosage Form
}

National Cancer Institute

\section{Source}

National Cancer Institute. Suspension for Spray Dosage Form. NCI Thesaurus. Code C162027.

Liquid preparation consisting of a suspension intended for use in the preparation of a spray. 